\title{
圆 \\ Parasites of domestic and wild animals in South Africa. XLV. Helminths of dairy calves on dry-land Kikuyu grass pastures in the Eastern Cape Province
}

\author{
I.G. HORAK ${ }^{1}$, URSULA EVANS ${ }^{2}$ and R.E. PURNELL ${ }^{3}$
}

\begin{abstract}
HORAK, I.G., EVANS, URSULA \& PURNELL, R.E. 2004. Parasites of domestic and wild animals in South Africa. XLV. Helminths of dairy calves on dry-land Kikuyu grass pastures in the Eastern Cape Province. Onderstepoort Journal of Veterinary Research, 71:291-306

Successive pairs of approximately 4-month-old Friesland bull calves, raised under worm-free conditions, were exposed to helminth infection for 14 days on dry-land Kikuyu grass pastures at 28-day to monthly intervals, on a coastal farm in a non-seasonal rainfall region of the Eastern Cape Province. With the exception of one pair of calves exposed for 28 days, this procedure was repeated for 28 consecutive months from December 1982 to March 1985. The day after removal from the pastures one calf of each pair was slaughtered and processed for helminth recovery and the other 21 days later. Both members of the last four pairs of calves were killed 21 days after removal from the pastures.

Sixteen nematode species were recovered from the calves, and infection with Ostertagia ostertagi was the most intense and prevalent, followed by Cooperia oncophora. The calves acquired the greatest number of nematodes from the pastures from June to October of the first year and from June to August of the second year of the survey. Few worms were recovered from the tracer calves examined from November or December to March or April in each year of the survey. The seasonal patterns of infection with Cooperia spp., Haemonchus placei, Nematodirus helvetianus, Oesophagostomum spp., O. ostertagi and Trichostrongylus axei were all similar and were negatively correlated to atmospheric temperature and evaporation. Slight to moderate arrest in the development of fourth stage larvae occurred from July to September in Cooperia spp., April to July in $\mathrm{H}$. placei, and August to October in O. ostertagi and Trichostrongylus spp. during the first year of the survey. Too few worms were present in the second year to determine a seasonal pattern of arrest. Species survival during the hot and windy summer months appeared to be achieved via a combination of arrested larval development and an ageing residual population of adult worms in the host, and a small extant population of infective larvae on the pastures.
\end{abstract}

Keywords: Cooperia spp., Eastern Cape Province, Haemonchus placei, Kikuyu grass pastures, Nematodirus helvetianus, Oesophagostomum spp., Ostertagia ostertagi, seasonality, tracer calves, Trichostrongylus axei

1 Department of Zoology and Entomology, University of the Free State, P.O. Box 339, Bloemfontein, 9300 South Africa

25 Diana Close, Constantia, 7800 South Africa

3 Pfizer Central Research, Sandwich, Kent, England

Present address: Cherry Trees, Wootton Close, Petham, CT4 5WE, England

Accepted for publication 7 April 2004-Editor

\section{INTRODUCTION}

During the past 40 years large tracts of land along the southern coast of the Eastern Cape Province, South Africa, stretching from approximately East London ( $\left.33^{\circ} 01^{\prime} \mathrm{S}, 27^{\circ} 53^{\prime} \mathrm{E}\right)$ in the east to Humansdorp (3402' $\left.S, 24^{\circ} 46^{\prime} \mathrm{E}\right)$ in the west, have been planted to Kikuyu grass (Pennisetum clandestinum). This is a temperate zone with frost-free winters and 
non-seasonal rainfall. The summers are hot and windy and often interspersed with short droughts. The dry-land Kikuyu grass pastures are usually heavily fertilized and are highly productive, and because the grass is not suitable for making hay it is best utilized by grazing animals, particularly dairy cows and replacement heifers. The stocking rate is high and most dairy farmers consider nematode parasites a constraint to the raising of stock.

Several surveys of helminths parasitizing small domestic ruminants on farms in the Eastern Cape Province and adjacent southern regions of the Western Cape Province have been conducted. Rossiter (1964) and Muller (1968) have examined sheep on coastal farms, Barrow (1964) and Horak (2003) sheep on inland farms, and Boomker, Horak \& Maclvor (1989), Fivaz, Horak \& Williams (1990) and Horak, Knight \& Williams (1991) have done so for goats on inland farms. No such studies have been conducted on the helminths of cattle in this region.

This paper describes the seasonal patterns of helminth infection in dairy calves on a coastal farm near Alexandria. The research was conducted a number of years ago, but for various reasons was not published. Despite the passage of time the results remain unique as this is the first survey of helminths in cattle in this region, and the seasonal intensity of infection differs considerably from that recorded in cattle elsewhere in South Africa. The ixodid ticks recovered from the survey animals have been reported separately (Horak 1999).

\section{MATERIALS AND METHODS}

\section{Study site}

The farm "Glen Dye" (3345' S, 26²9' E; Alt. 137 m) is situated approximately $3 \mathrm{~km}$ from the coast south of Alexandria, Eastern Cape Province, and at the time of the survey was 232 ha in extent. With the exception of patches of indigenous coastal forest, retained for windbreaks and shade, virtually the entire farm has been planted to Kikuyu grass and divided into paddocks approximately 1 ha in size. These paddocks are not irrigated, but are heavily fertilized, and are used mainly as grazing for dairy cattle. Rainfall is non-seasonal and the long-term mean annual total is $830 \mathrm{~mm}$, virtually equally distributed between the first and second halves of the year. Total annual precipitation is supplemented by heavy coastal mist. At the time of the survey the farm was stocked with approximately 200 Friesland cows, 90 replacement heifers, 30 beef cattle and 40 mutton-breed sheep.

Four hectares of pasture on a south facing incline were divided into four 1 ha fenced paddocks and allocated to the study. Prior to fencing this particular bit of pasture had been grazed by cattle and horses. Subsequent to fencing five Friesland calves were rotated through the four camps, and on occasion dairy cows also, to ensure their contamination with worm eggs. All cattle were removed during November 1982 and on 29 November 1982, 15 9month-old Friesland heifer calves were placed in one of the four paddocks and thereafter rotated through them. This ensured that the camps were evenly seeded with helminth eggs. None of the heifers was treated with an anthelmintic during their sojourn on the pastures.

The heifers were artificially inseminated and removed from the paddocks shortly before each one was due to calve. The first heifers were taken off during May and the last during September 1984.

\section{Faecal worm egg counts}

On 29 November 1982 and 4 January 1983, and at approximately 4-weekly intervals thereafter until January 1984, faeces were collected from each heifer for faecal worm egg counts. Once the faeces required for individual egg counts had been weighed the remainder were pooled, thoroughly mixed and a single faecal culture made for larval differentiation (Reinecke 1973). Nematodirus and Trichuris eggs were counted separately from those of the other nematodes. The eggs of the other nematodes were allocated to the various genera in proportion to the third stage infective larvae harvested from the faecal cultures.

\section{Larval collections from herbage}

On 29 November 1982, and on 4 January 1983 and at 4-weekly intervals thereafter until January 1984 , when sampling ceased, herbage was collected during the morning in a W-pattern from 144 approximately equidistant points in the four survey paddocks. Four separate pinches of grass, taken at soil level, were collected by hand in the vicinity of each of these points and the samples so collected placed in a large plastic bag, which was sealed and transported to the laboratory at Grahamstown.

At the laboratory the herbage was weighed, thoroughly mixed and $250 \mathrm{~g}$, consisting of pinches of grass taken from the total, was placed in a bucket 
with $10 \ell$ of water and $1 \mathrm{~m} \ell$ of Tween 80 . The remainder was put in a large container, and water and Tween 80 were added at the rate of $10 \ell$ per $250 \mathrm{~g}$ of herbage and $1 \mathrm{~m} \ell$ per $10 \ell$ of water respectively. The herbage was left to soak overnight and removed the following morning, at the same time squeezing out water trapped in it. The grass from the larger container was discarded, while that from the bucket was placed on a tray in a drying-oven at $56^{\circ} \mathrm{C}$. The remaining contents of both containers were allowed to sediment overnight and the supernatent fluid was discarded. The sediment was passed through a sieve with $38 \mu \mathrm{m}$ apertures and the material retained on the sieve was Baermannized overnight through a sieve with $300 \mu \mathrm{m}$ apertures. The liquid drawn from the Baermann funnel the following morning was allowed to sediment overnight and the supernatent fluid was discarded. Third stage infective larvae in a representative sample of the sediment were counted and converted to larvae per kg of dry herbage.

\section{Survey animals}

At regular intervals Friesland bull calves, approximately 1 week old, were removed from their dams and raised until the age of approximately 4 months in individual pens, with expanded metal floors, which were cleaned daily. These conditions were intended to prevent the calves acquiring infection with helminths. At 4-weekly intervals two of the older calves were each drenched with albendazole (Valbazen: Pfizer Animal Health) at $15 \mathrm{mg} / \mathrm{kg}$ body mass to eliminate nematodes they may have acquired during rearing, and once every 28 days from 3 December 1982 to 3 January 1984, and thereafter once every calendar month from 13 February 1984 to 5 March 1985, 29 separate pairs of these calves were placed on the pastures with the 15 heifers for a period of 14 days. In December 1984 the calves remained on the pastures for 28 days. During September 1984 the last of the heifers were removed from the experimental paddocks and in order to make use of the excess herbage that now became available, other cattle were allowed to graze these plots with the tracer calves. None of the tracer calves was treated with an anthelmintic while on the pastures or thereafter.

At the conclusion of their periods of exposure the calves were transported to Grahamstown, and on the following day one was killed and its gastrointestinal tract and its contents processed for helminth recovery (day 0 tracer). The other calf was housed indoors in a cage with a steel-mesh floor and maintained under conditions intended to pre- clude the acquisition of further helminth infection. This calf was killed 21 days after it had been taken off the pastures (day 21 tracer) and its lungs and its gastro-intestinal tract and contents processed for the recovery of helminths. The last four pairs of calves were all slaughtered 21 days after their respective periods of exposure.

\section{Necropsy procedure}

The contents of the abomasa and small intestines of the day 0 tracer calves were washed over sieves with $38 \mu \mathrm{m}$ apertures and their caecal and colonic contents over sieves with $150 \mu \mathrm{m}$ apertures. The mucosae of all these organs were subjected to pep$\sin / \mathrm{HCl}$ digestion (Reinecke 1973) and washed over sieves with $38 \mu \mathrm{m}$ apertures. All material retained in the sieves was collected and preserved with formalin. Since no worms had been recovered from the digested material of the first 12 day 0 tracer calves examined, digestion of the mucosae of the caecum and colon was discontinued.

The contents of the abomasa and the digests of the abomasal mucosae of the day 21 tracer calves were washed over sieves with $38 \mu \mathrm{m}$ apertures, and the contents of their small and large intestines over sieves with $150 \mu \mathrm{m}$ apertures. No digests were made of the mucosae of the latter organs. The trachea and the bronchi of the right lungs of these calves were slit open, and the lungs thoroughly washed. The washings were sieved over a sieve with $150 \mu \mathrm{m}$ apertures and the sieve contents examined for lungworms.

\section{Helminth identification and counts}

Adult helminths in two or three $1 / 32^{\text {nd }}$ to $1 / 128^{\text {th }}$ representative samples of the processed material were identified to genus level and counted under a stereoscopic microscope. The size of the aliquots was decreased to between $1 / 200^{\text {th }}$ and $1 / 500^{\text {th }}$ in eight of the calves when the nematodes initially seen in a larger aliquot were deemed to be particularly numerous. All male worms in the aliquots were collected, and the posterior ends of the larger species, namely $H$. placei and N. helvetianus, and the anterior and posterior ends of the Oesophagostomum spp., were cut off to facilitate examination. After the bursae and spicules of all the male worms and the anterior ends of the Oesophagostomum spp. had been cleared in warm lactophenol, they were specifically identified under a standard binocular microscope. The female worms encountered were allocated to species in proportion to the number of males identified within 
that genus and species. Third and fourth stage larvae were also counted. They were collected from the aliquots, placed in a drop of water and covered with a cover-slip before identification under a standard binocular microscope using the descriptions by the authors listed in Reinecke (1973). After removal of the representative samples from the processed ingesta of the day 21 tracer calves the remainder of the small intestinal contents was examined macroscopically for cestodes and that of the large intestine for adult Oesophagostomum and Trichuris species. This was not done for the day 0 tracer calves as their helminths were still immature and hence difficult to see with the naked eye.

The 28-day intervals between the slaughter of the various day 0 tracer calves exposed from December 1982 to January 1984 resulted in two of these calves being killed during August 1983, one on 3 August and the other on 31 August. To accommodate the worm burdens of these calves separately the month of August 1983 appears twice in the figures depicting worm burdens.

\section{Climatological data}

Daily minimum and maximum atmospheric temperatures, rainfall, evaporation, daily hours of sunshine and wind-run ( $\mathrm{km} / 24 \mathrm{~h}$ ) were measured on "Glen Dye".

\section{RESULTS AND DISCUSSION}

\section{Climate}

The greatest mean temperatures, evaporation and wind-run and longest hours of sunlight were generally recorded from November to April (Fig. 1). Rain fell during every month of the survey with monthly totals in excess of $100 \mathrm{~mm}$ during July 1983, June 1984 and January 1985.

\section{Heifers}

The differential faecal worm egg counts of the 15 heifers are summarized in Table 1. The 35-day interval between the first worm egg counts and the second and the approximately 28-day intervals thereafter resulted in two sets of counts being done during January and March 1983 and none in December 1982 and February 1983.

Larvae of six nematode genera were recovered from the faecal cultures. Mean faecal worm egg counts rose from November 1982 and reached a peak from late March to August 1983. They declined there- after to their lowest levels in December 1983 and January 1984 (Fig. 2).

Although the larvae of Bunostomum sp. were present in the faecal cultures of the heifers on four occasions, no worms of this genus were recovered from any of the tracer calves. This is possibly because of the pulmonary migration of Bunostomum sp. larvae and its protracted life cycle (Reinecke 1983). The output of Cooperia spp. eggs by the heifers was never very high, but effectively dropped to zero from October 1983, while those of Haemonchus, Oesophagostomum and Ostertagia decreased from November onwards. These decreases are probably age-associated (Reinecke 1983) and occurred as the heifers reached 2 years of age during November 1983. However, the egg output of Trichostrongylus spp. remained fairly constant throughout 1983 . Eggs of Moniezia benedini were present in the faeces of the heifers from January to April and again in September 1983. The seasonal pattern of egg excretion by this cestode corresponds closely to the acquisition of infection noted in the tracer calves examined during 1983 (Fig. 10).

\section{Herbage larval counts}

The numbers of larvae recovered per kg of dry herbage and the mean faecal worm egg counts of the heifers are graphically illustrated in Fig. 2 . The heifers deposited nematode eggs on the pastures from December 1982, but the first larvae were collected from the herbage only in April 1983 and reached a peak during September and October. No larvae were recovered from the herbage during July 1983 and January 1984, and no herbage samples were taken during December 1983.

\section{Tracer calves}

The total number of helminths of each species collected from the 29 pairs of tracer calves and their prevalence in these animals are summarized in Table 2.

Sixteen nematode species, of which Cooperia oncophora and Ostertagia ostertagi were the most numerous and prevalent, were recovered from the tracer calves. Moniezia benedeni was the only cestode present.

With the exception of September 1983 when large numbers of larvae were collected from the herbage and large numbers of helminths were recovered from the tracer calves, the numbers of nematodes in the tracer calves did not match the seasonal 

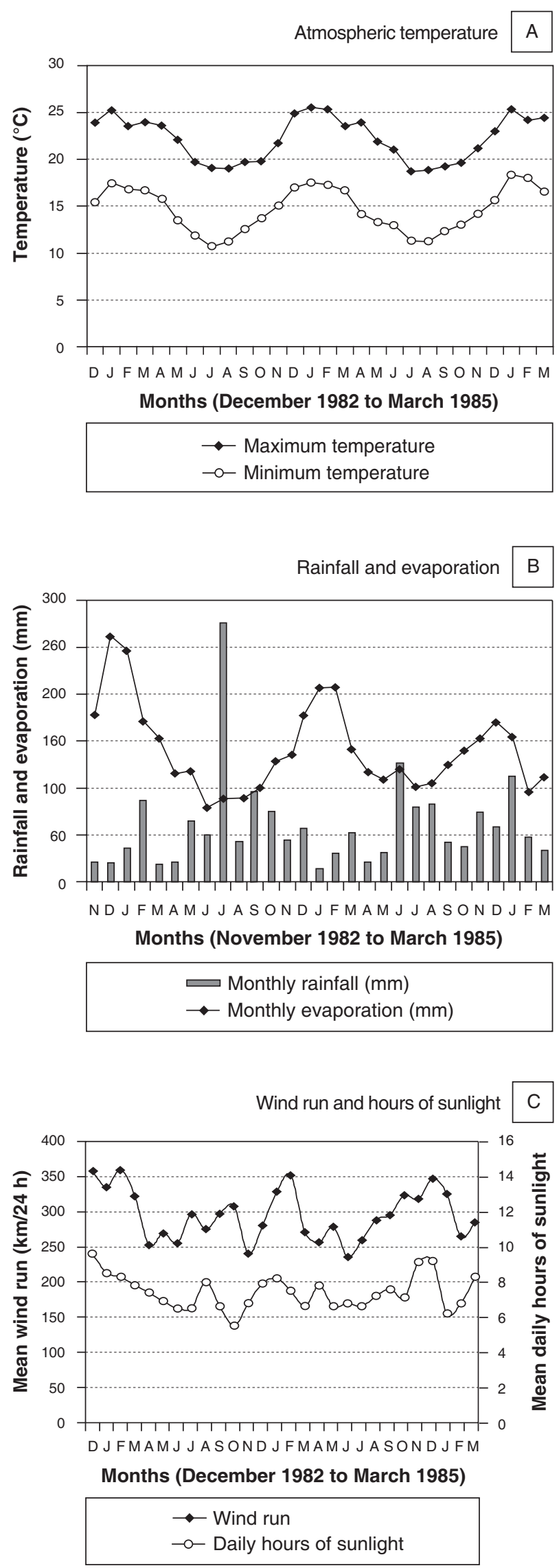

FIG. 1 Climate on the farm "Glen Dye", Eastern Cape Province. A) mean minimum and maximum atmospheric temperatures, B) total monthly rainfall and mean monthly evaporation, and $\mathrm{C}$ ) mean daily hours of sunshine and wind run $(\mathrm{km} / 24 \mathrm{~h})$

occurrence of larvae on the herbage, but rather followed the faecal worm egg counts of the heifers (Fig. 2 and 3). Although herbage collections ceased in January 1984, the seasonal pattern of infection in the tracer calves exposed thereafter indicated that acquisition of infection followed a pattern fairly similar to that recorded during 1983. The markedly lower and shorter peak in intensity of infection in the tracer calves during 1984, can be ascribed to the fact that the 15 heifers used to "seed" the pasture with infection were by now a year older and had become relatively immune to infection and hence voided considerably fewer worm eggs in their faeces (Table 1). The animals with which the heifers were replaced during September 1984 were adult cows, and thus also unlikely to have contributed much to pasture contamination.

Excluding the day 0 tracer calves slaughtered on 3 and 31 August 1983 respectively, in both of which the intensity of infection was very high, and the day 0 tracers slaughtered during June and July 1984, both of which were purging, the intensity of infection of the day 0 and the day 21 tracer calves was generally very similar. The intensity of infection in both calves in each pair exceeded 29000 worms during June and 69000 worms from July to October 1983. During 1984 the burdens of both calves of each pair exposed from June to August exceeded 10000 worms. The burdens of the tracer calves exposed from December 1982 to March 1983, December 1983 to May 1984, and September 1984 to March 1985 were always modest and never exceeded 3500 worms. There appeared to be a distinctly negative correlation between the peaks in seasonal occurrence of the nematodes acquired from the pastures by the tracer calves and the mean monthly atmospheric temperatures and evaporation (Fig. $1 \mathrm{~A}$ and Fig. 3).

The seasonal pattern of infection in the calves is similar to that recorded by Muller (1968) in sheep on artificial pastures close to the coast in the southern Western Cape Province. He found that conditions for the acquisition of infection of all nematode species were optimal during autumn, winter and early spring, and stated that the relatively low level of infection during the summer "is in all probability the result of light pasture contamination combined 
Parasites of domestic and wild animals in South Africa. XLV

TABLE 1 Differential faecal worm egg counts of 15 Friesland heifers on Kikuyu grass pastures on the farm "Glen Dye", Eastern Cape Province

\begin{tabular}{|c|c|c|c|c|c|c|c|c|c|c|}
\hline \multirow{2}{*}{ Date } & \multicolumn{7}{|c|}{$\begin{array}{l}\text { Average number of eggs per } g \text { of faeces calculated from larvae } \\
\text { recovered in faecal cultures }\end{array}$} & \multicolumn{3}{|c|}{$\begin{array}{l}\text { Eggs only identified during faecal } \\
\text { worm egg counts }\end{array}$} \\
\hline & Bun & Coop & Haem & Oes & Ost & Trich & Total & Nemato & Trichuris & Moniezia \\
\hline \multicolumn{11}{|l|}{1982} \\
\hline $29 \mathrm{Nov}$ & 0 & 22 & 0 & 0 & 34 & 11 & 67 & 0 & 0 & 0 \\
\hline \multicolumn{11}{|l|}{1983} \\
\hline 04 Jan & 0 & 46 & 78 & 17 & 38 & 33 & 212 & 4 & 0 & 0 \\
\hline 31 Jan & 46 & 12 & 7 & 116 & 54 & 33 & 268 & 0 & 0 & Pos \\
\hline $01 \mathrm{Mar}$ & 1 & 14 & 2 & 10 & 31 & 19 & 77 & 0 & 0 & Pos \\
\hline 29 Mar & 0 & 22 & 41 & 36 & 67 & 21 & 187 & 0 & 7 & Pos \\
\hline $27 \mathrm{Apr}$ & 0 & 25 & 169 & 32 & 101 & 33 & 360 & 0 & 3 & Pos \\
\hline 24 May & 5 & 11 & 54 & 1 & 19 & 40 & 130 & 0 & 0 & 0 \\
\hline 21 Jun & 0 & 60 & 76 & 39 & 76 & 76 & 327 & 0 & 0 & 0 \\
\hline $19 \mathrm{Jul}$ & 0 & 9 & 97 & 41 & 32 & 51 & 230 & 0 & 0 & 0 \\
\hline 16 Aug & 3 & 12 & 59 & 96 & 32 & 45 & 247 & 0 & 0 & 0 \\
\hline 13 Sep & 0 & 12 & 14 & 2 & 50 & 45 & 123 & 0 & 0 & Pos \\
\hline 11 Oct & 0 & 0 & 12 & 25 & 17 & 59 & 113 & 0 & 0 & 0 \\
\hline $08 \mathrm{Nov}$ & 0 & 0 & 3 & 1 & 13 & 63 & 80 & 0 & 0 & 0 \\
\hline $06 \mathrm{Dec}$ & 0 & 0 & 2 & 7 & 10 & 42 & 61 & 0 & 0 & 0 \\
\hline \multicolumn{11}{|l|}{1984} \\
\hline 03 Jan & 0 & 1 & 6 & 3 & 8 & 18 & 36 & 0 & 0 & 0 \\
\hline
\end{tabular}

Bun = Bunostomum Ost $=$ Ostertagia
Coop = Cooperia

Trich $=$ Trichostrongylus
Haem = Haemonchus

Nemato $=$ Nematodirus
Oes = Oesophagostomum
Worm eggs and infective larvae

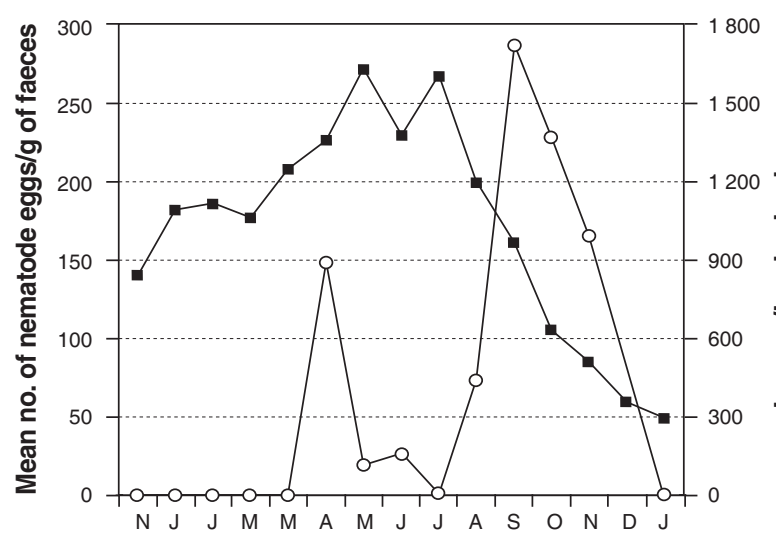

Months (November 1982 to January 1984)

$$
\begin{aligned}
& - \text { Eggs/g faeces } \\
& \text {-ం Larvae/kg dry herbage }
\end{aligned}
$$

FIG. 2 Three point moving mean faecal worm egg counts of 15 untreated heifers and mean numbers of infective nematode larvae per kg of dry herbage on the farm "Glen Dye", Eastern Cape Province. (Two sets of egg counts and larval collections in January and in March 1983, and none in December 1982 and February 1983)

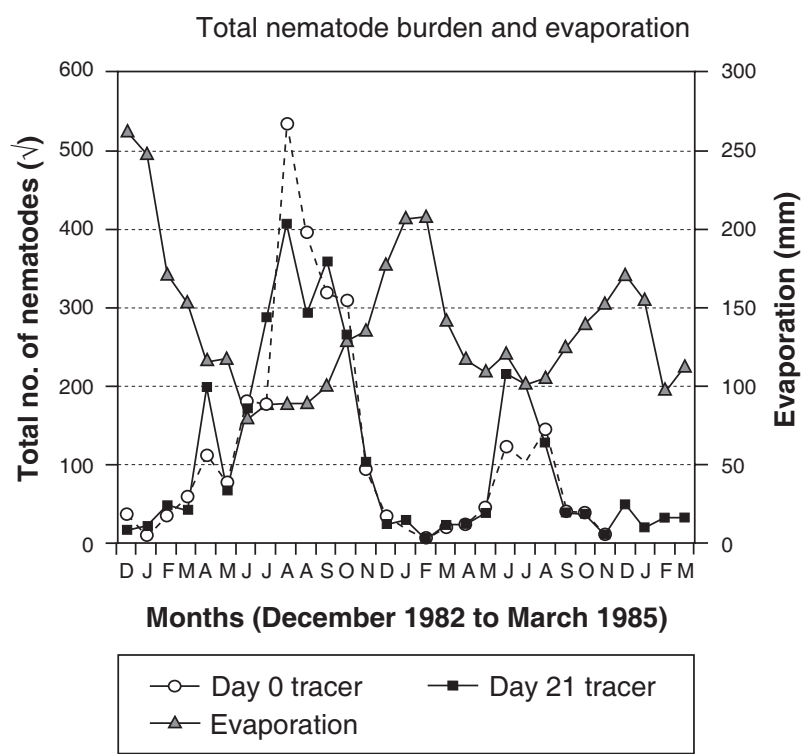

FIG. 3 Mean monthly evaporation on the pastures and the seasonality of nematode infection in tracer calves on the farm "Glen Dye", Eastern Cape Province. Two sets of calves were examined during August 1983 
I.G. HORAK, URSULA EVANS \& R.E. PURNELL

TABLE 2 Helminths collected from 58 tracer bull calves on Kikuyu grass pastures on the farm "Glen Dye", Eastern Cape Province

\begin{tabular}{|c|c|c|c|c|c|}
\hline \multirow[b]{2}{*}{ Nematode species } & \multicolumn{4}{|c|}{ Total number of helminths } & \multirow{2}{*}{$\begin{array}{l}\text { Mean burden }(\% \text { of } \\
\text { animals infected) }\end{array}$} \\
\hline & $\begin{array}{l}3^{\text {rd }} \text { stage } \\
\text { larvae }\end{array}$ & $\begin{array}{l}4^{\text {th }} \text { stage } \\
\text { larvae }\end{array}$ & Adults & Total & \\
\hline Cooperia spp. & 7948 & 212717 & + & 220665 & $3805(55)$ \\
\hline Cooperia macmasteri & - & - & 56004 & 56004 & $966(59)$ \\
\hline Cooperia oncophora & - & - & 235724 & 235724 & $4064(76)$ \\
\hline Cooperia punctata & - & - & 8952 & 8952 & $154(41)$ \\
\hline Cooperia spatulata & - & - & 10531 & 10531 & $182(36)$ \\
\hline Dictyocaulus viviparus & 0 & 0 & 10 & 10 & $0.2(3)$ \\
\hline Haemonchus placei & 10590 & 29120 & 12359 & 52069 & $898(74)$ \\
\hline Nematodirus helvetianus & 1688 & 4695 & 7450 & 13833 & $238(60)$ \\
\hline Oesophagostomum spp. & 1369 & 3371 & + & 4740 & $82(52)$ \\
\hline Oesophagostomum radiatum & - & - & 419 & 419 & $7(38)$ \\
\hline Oesophagostomum venulosum & - & - & 347 & 347 & $6(14)$ \\
\hline Ostertagia ostertagi & 89959 & 344298 & 391094 & 825351 & $14230(98)$ \\
\hline Strongyloides sp. & 15586 & 946 & 0 & 16532 & $285(35)$ \\
\hline Trichostrongylus spp. & 2580 & 29280 & + & 31860 & $549(57)$ \\
\hline Trichostrongylus axei & - & - & 54246 & 54246 & $935(52)$ \\
\hline Trichostrongylus colubriformis & - & - & 220 & 220 & $4(5)$ \\
\hline Trichostrongylus falculatus & - & - & 12 & 12 & $0.2(2)$ \\
\hline Trichostrongylus rugatus & - & - & 325 & 325 & $6(9)$ \\
\hline Trichuris sp. & \multicolumn{2}{|c|}{19 (immatures) } & 419 & 438 & $8(41)$ \\
\hline \multicolumn{4}{|l|}{ Total } & 1532278 & $26419(100)$ \\
\hline $\begin{array}{l}\text { Cestode species } \\
\text { Moniezia benedeni }\end{array}$ & \multicolumn{3}{|l|}{$\begin{array}{l}\text { Scolices } \\
43\end{array}$} & $\begin{array}{l}\text { Total } \\
43\end{array}$ & $0.7(22.4)$ \\
\hline
\end{tabular}

$+=$ Adults of these genera identified specifically

$-=3^{\text {rd }}$ and $4^{\text {th }}$ stage larvae of these species identified only to generic level

with the deleterious effects of intense sunlight, heat and evaporation on the free-living stages." These results are similar to those obtained by Williams, Knox, Baumann, Snider, Kimball \& Hoerner (1983) for a similar spectrum of nematode species in tracer calves exposed on artificial pastures contaminated by yearling cattle in the temperate Red River Valley region of Louisiana, United States of America. Tracer calves grazing lucerne pastures in western Argentina also acquired scant infection during summer, whereas considerably larger burdens were recorded in autumn-grazed calves (Suarez, Busetti \& Fort 1992). Unfortunately no calves were exposed during winter in the latter study, thus precluding further comparisons.

Urquhart, Armour, Duncan, Dunn \& Jennings (1987) state that several environmental factors that affect the microhabitat of the free-living stages of parasitic nematodes, are vital for their development and survival. Moderate temperatures and high humidity favour development, while cool temperatures prolong survival. According to these authors microclimatic humidity depends not only on rainfall and temperature, but also on other elements such as soil structure, vegetation type and drainage. On "Glen Dye" mild winter temperatures and the lush nature of the Kikuyu pastures after good rainfall probably ensured adequate temperature and humidity for larval development and survival during the cooler months of the year. However, rotational grazing of the pastures prevented the formation of a significant "mat" between the soil and the herbage, which, according to Urquhart et al. (1987), holds a permanent store of moisture in which the relative humidity remains high even after weeks of drought. The absence of a "mat" coupled with the high rate of evaporation, induced by long hours of sunlight and high wind-run, and the sandy nature of the soil, all contributed towards low microclimatic humidity in the summer months, and hence the paucity of infective larvae.

The adult and larval burdens of Cooperia spp., Haemonchus placei, Nematodirus helvetianus, Oesophagostomum spp., O. ostertagi and Trichostrongylus spp. of the tracer calves are graphically illustrated in Fig. 4-9. 
Parasites of domestic and wild animals in South Africa. XLV

FIG. 4 Seasonality of A) Cooperia spp. larvae, B) adult Cooperia mcmasteri, and C) adult Cooperia oncophora in tracer calves on the farm "Glen Dye", Eastern Cape Province. Two sets of calves were examined during August 1983

\section{Cooperia spp.}

Cooperia oncophora followed by Cooperia macmasteri were the most numerous and prevalent of the four Cooperia spp. recovered. In earlier surveys in cattle in the hot and semi-arid regions in the north and north-west of South Africa, in sub-tropical regions in the north-east and on the cool Highveld, Cooperia pectinata and Cooperia punctata were the most numerous, if not the only species present (Reinecke 1960b, Horak 1978; Horak \& Louw 1978; Malan, Reinecke \& Roper 1982; Dreyer, Fourie \& Kok 1999; Louw 1999). In this survey, however, only small numbers of $C$. punctata and no $C$. pectinata were recovered. Both $C$. pectinata and $C$. punctata and also Cooperia spatulata have previously been recorded in sheep on artificial pastures close to the coast in the south-eastern Western Cape Province (Muller 1968).

The seasonal pattern of infection of Cooperia spp. larvae and those of the adults of the four Cooperia spp. were very similar (Fig. 4). During 1983 burdens in excess of 23000 worms comprising all developmental stages of this genus were recorded in calves exposed from 22 June to 14 September. In both 1983 and 1984 the largest worm burdens were present in calves exposed during July, with the single largest burden of 117952 worms present in the day 0 tracer calf exposed on 20 July and slaughtered on 3 August 1983, compared to the highest burden of only 3110 worms in one of the four tracer calves exposed during July and August 1984.

The development of third and fourth stage Cooperia spp. larvae to fourth stage larvae and adult worms is evident from the burdens of successive pairs of day 0 and day 21 tracer calves (Fig. $4 A-C)$. The fourth stage larvae still present in the day 21 tracers represent worms that have been arrested in their development. However, arrested development was not a prominent feature in this genus, with the highest proportion accounting for only $17 \%$ of the total Cooperia spp. burden in the day 21 tracer calf exposed during September 1983 (early spring). The low percentage of arrested larvae is similar to that observed by Smeal, Fraser \& Robinson (1980b) in calves on pastures on the Northern Tablelands and on the north coast of New
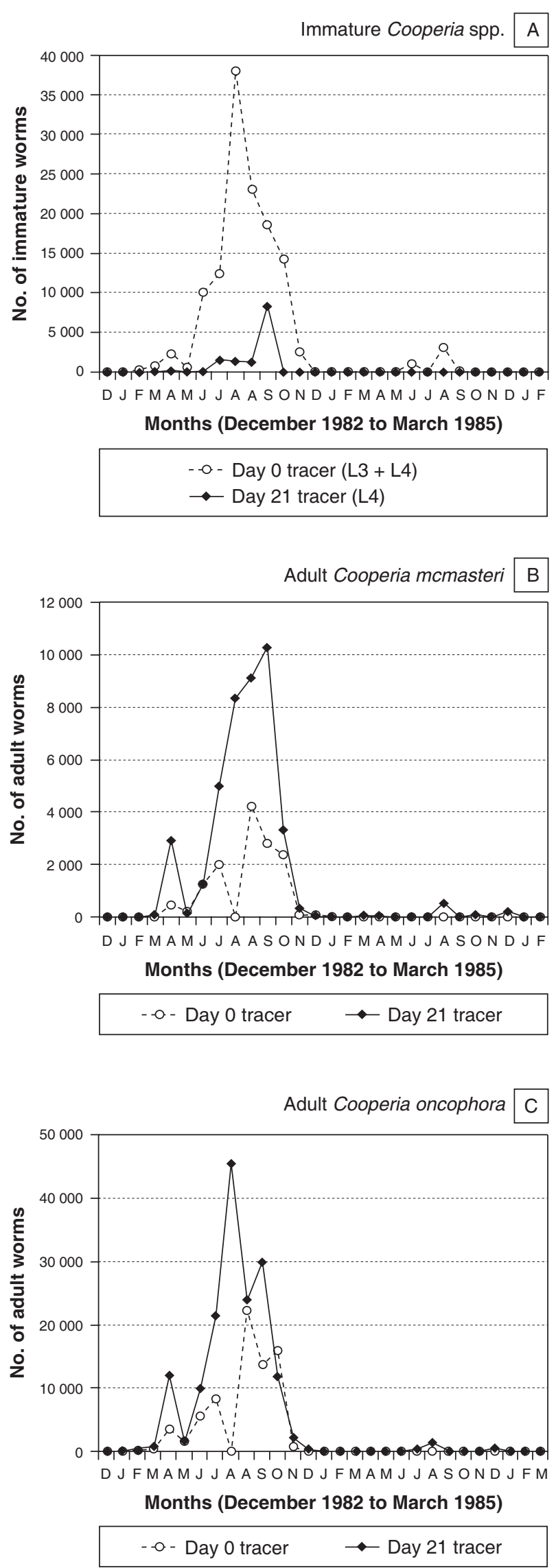

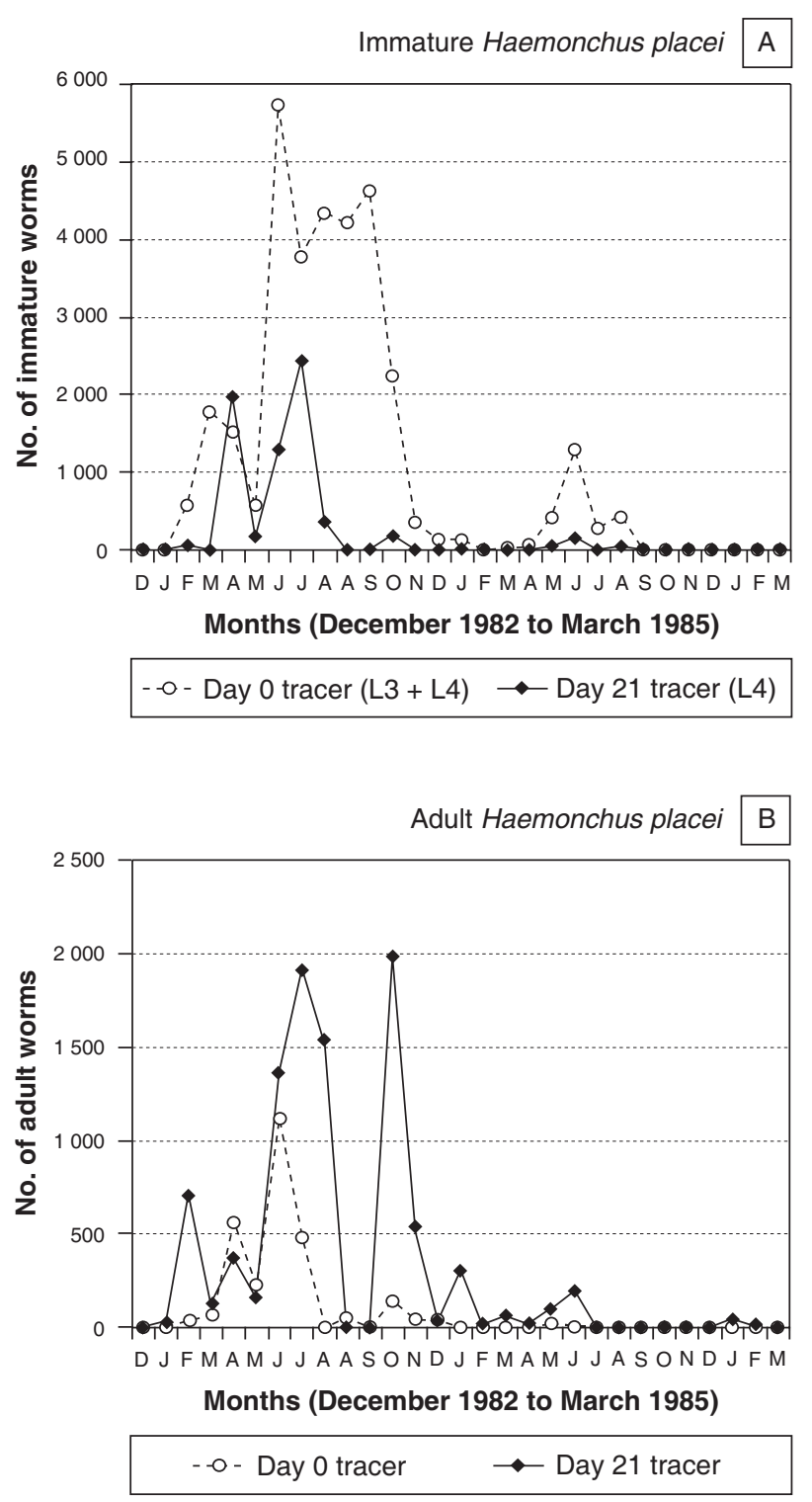

FIG. 5 Seasonality of A) immature and B) adult Haemonchus placei in tracer calves on the farm "Glen Dye", Eastern Cape Province. Two sets of calves were examined during August 1983

South Wales, Australia. They recorded large burdens of Cooperia spp. in calves on pastures that had been contaminated in autumn, but with a single exception of $32.4 \%$, arrested larvae never exceeded $15 \%$ of the total burden.

A considerable number of adult worms of all four Cooperia spp. were already present in the day 0 tracer calves killed 15 days after their first exposure on the pastures (Fig. 4B and C). This can be attributed to the fourth larval moult taking place as soon as 8 days after infection in both $C$. pectinata and $C$. punctata (Keith 1967; Reinecke 1973), and hence probably also in other Cooperia spp. that infect cattle.

\section{Dictyocaulus viviparus}

In South Africa infection with $D$. viviparus is confined to animals in the Western Cape Province and in isolated foci in the mist-belt of the Drakensberg in KwaZuluNatal and Mpumalanga Provinces. It is common in cattle on irrigated pastures on the Highveld of Gauteng Province (Reinecke 1983). Small numbers have also been recovered from blue wildebeest, Connochaetes taurinus, in a hot Lowveld environment (Horak, De Vos \& Brown 1983). The high rate of evaporation on the dry-land pastures in this survey probably had a severely limiting effect on the survival of free-living larvae and hence the small numbers of worms in the tracer calves.

\section{Haemonchus placei}

The highest intensity of infection was recorded in tracer calves examined from June to October 1983 and during June 1984. Adult worms were already present in the day 0 tracer calves 15 days after their first exposure to infestation on the pastures. The day 21 tracers removed from the pastures in late August and during September 1983 harboured no H. placei whatsoever (Fig. 5), but both were infected with large numbers of immature and adult $O$. ostertagi and Trichostrongylus axei (Fig. 8 and 9). It could be that a density-dependent reaction with elimination of $H$. placei had occurred as postulated by Muller (1968) for the interaction that took place between Ostertagia spp., $T$. axei and $H$. contortus, to the detriment of the latter species, in sheep on coastal pastures in the Western Cape Province.

A comparison between the burdens of third and fourth stage $H$. placei larvae of the day 0 tracer calves with those of their day 21 partners shows that arrest in larval development was most prevalent in infection acquired during autumn and winter in 1983, and declined during late winter and spring (Fig. 5A). The intensity of infection in 1984 was too low to ascertain a reliable seasonal trend in larval arrest. A similar autumn and winter pattern in both the acquisition of infection and arrest in larval development has been recorded in calves grazed on pastures contaminated with Haemonchus spp. during autumn on the sub-tropical north coast of New South Wales (Smeal et al. 1980b).

In South Africa arrest in larval development exceeded $90 \%$ in Haemonchus spp. in tracer calves grazed on irrigated pastures on the Highveld of Gauteng 


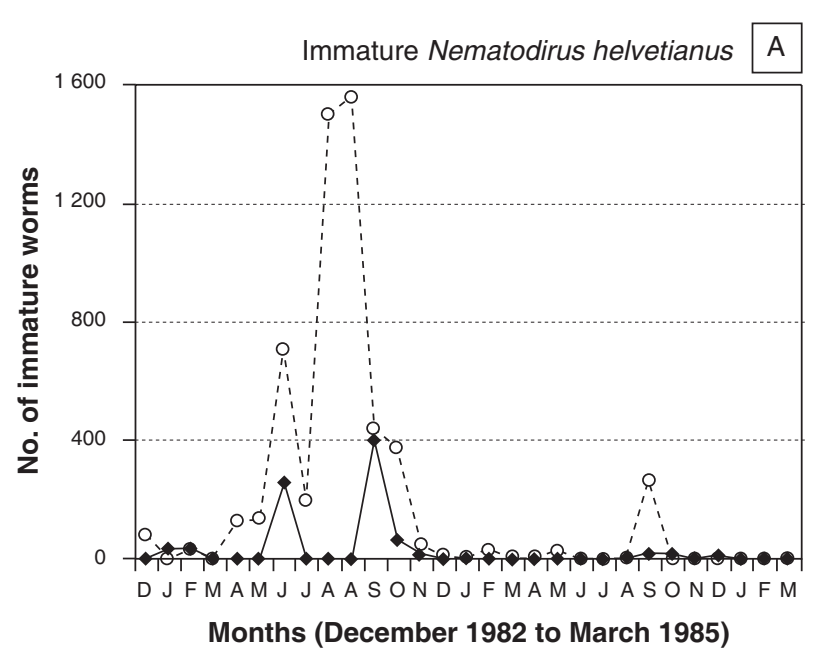

- - Day 0 tracer $(\mathrm{L} 3+\mathrm{L} 4) \longrightarrow$ Day 21 tracer $(\mathrm{L} 4)$

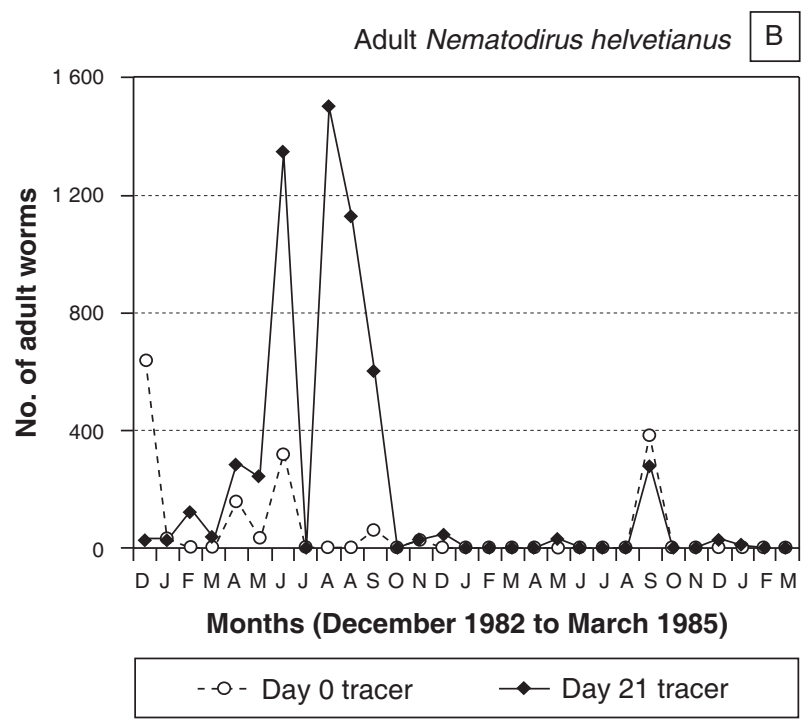

FIG. 6 Seasonality of A) immature and B) adult Nematodirus helvetianus in tracer calves on the farm "Glen Dye", Eastern Cape Province. Two sets of calves were examined during August 1983

Province between April or May and October (Horak \& Louw 1978). Although their worm burdens were very small it also appeared to be present from April to July in $H$. placei in cattle on the eastern Free State Highveld (Dreyer et al. 1999). The winters in the latter regions are dry and cold with frequent frosts. In the southern Bushveld of Limpopo Province, $100 \%$ arrest in development was recorded in $H$. placei in tracer calves grazing natural vegetation from April to July (Horak 1978), while no worms of this species were picked up from the pastures from August to October. In a separate survey in this province Schröder (1979) noted that no worms of this species were acquired from the pastures from May to October. The winters in this region are dry and warm. It would thus appear that Haemonchus spp. employ the same strategy of arrested larval development in order to survive within the host during winters that are either cold and dry or warm and dry. In the present study, however, the summer months seemed to be the least favourable for the acquisition of infective larvae from the pastures. This could have been caused by a failure of the larvae to survive, or because with increasing age the 15 heifers became more resistant to infection and excreted fewer nematode eggs with their faeces, or because the long hours of summer sun, increased wind run, with accompanying high evaporation on the southerly sloping pasture, dried the outer layer of faeces thus trapping infective larvae in dung-pats as described by Reinecke (1960a). Whatever the reason, the proportion of arrested larvae in the $H$. placei infections acquired by the tracer calves before summer was on the decline, and this did not appear to be a major strategy for over-summering on "Glen Dye".

\section{Nematodirus helvetianus}

Compared to the number of records for other nematodes parasitizing cattle in South Africa there are few for N. helvetianus. Reinecke (1983) states, "Although this parasite is rarely diagnosed in South Africa, it occurs in calves in the Western Cape Province, Eastern Cape Province and KwaZulu-Natal". $\mathrm{He}$ also said that its eggs are seldom detected in the faeces of calves older than 5 months. Nematodirus helvetianus would thus appear to be a parasite of young animals in the moist, temperate climates of the coastal provinces of South Africa. This assumption is supported by the findings of Reinecke (1960b), Horak (1978), Horak \& Louw (1978), Schröder (1979), Malan et al. (1982) and Fourie \& Horak (1990), none of who recovered worms of this species from cattle examined on inland farms.

Eggs of Nematodirus sp. were only present in the faeces of the heifers that grazed the survey camps with the tracer calves during January 1983 (when the heifers were 10 months old). In contrast, with the exception of two, every tracer calf exposed between December 1982 and December 1983 acquired infection with $N$. helvetianus. However, Smeal, Robinson \& Fraser (1980a), working in the central coastal region of New South Wales, Australia, recovered no worms of this genus from calves grazing pastures on which small numbers of Nematodirus spp. larvae were present. 
I.G. HORAK, URSULA EVANS \& R.E. PURNELL

The increase in the size of worm burdens in the tracer calves examined during autumn and winter and their decline in those exposed in summer (Fig. 6), are opposite to the findings of Eysker \& Van Miltenburg (1988) at Utrecht, in The Netherlands. They recovered between 19500 and $34700 \mathrm{~N}$. helvetianus from tracer calves grazing experimental paddocks during August (summer), compared to 790020000 worms from those grazing these paddocks during October (autumn). These differences confirm the importance of local environmental factors in determining the seasonality of this and other nematodes.

According to Herlich (1954) and Reinecke (1973) the fourth moult in $N$. helvetianus takes place between 14 and 16 days after infection. Judging by the number of adult worms already present in the day 0 tracer calves slaughtered 15 days after their first exposure to infection on the pastures, the fourth moult seems to have occurred sooner than the $14^{\text {th }}$ day in at least some of these worms.

\section{Oesophagostomum spp.}

Oesophagostomum radiatum is a parasite of cattle and is distributed throughout South Africa (Horak 1981a) from the arid north-west (Reinecke 1960b) to the subtropical north and north-east (Horak 1978; Schröder 1979; Malan et al. 1982), the coastal regions of KwaZulu Natal in the east (Hobbs 1961) and the non-seasonal rainfall regions of the south (Table 2). Oesophagostomum venulosum is present only in the southern regions of the Eastern and Western Cape Provinces (Horak 1981a), where it infects cattle, sheep and goats (Muller 1968; Reinecke, Kirkpatrick, Swart, Kriel \& Frank 1987; Reinecke \& Louw 1989; Horak et al. 1991; Horak 2003; Table 2).

In contrast to most other species, infection with Oesophagostomum spp. in the tracer calves was as intense during autumn and winter of the second year of the survey as it was in the first (Fig. 7). Most infection with these species was acquired in April and from June to October 1983 and from May to July 1984, the cooler months of the year. During the third year of the survey, however, adult $O$. radiatum was also present in all but one of the eight tracer calves examined from December 1984 to March 1985 (summer).

At Vryburg in the Northern Cape Province Reinecke (1960b) recorded the highest egg counts and intensity of infection of $O$. radiatum during winter, but he suggested that the calves had actually become
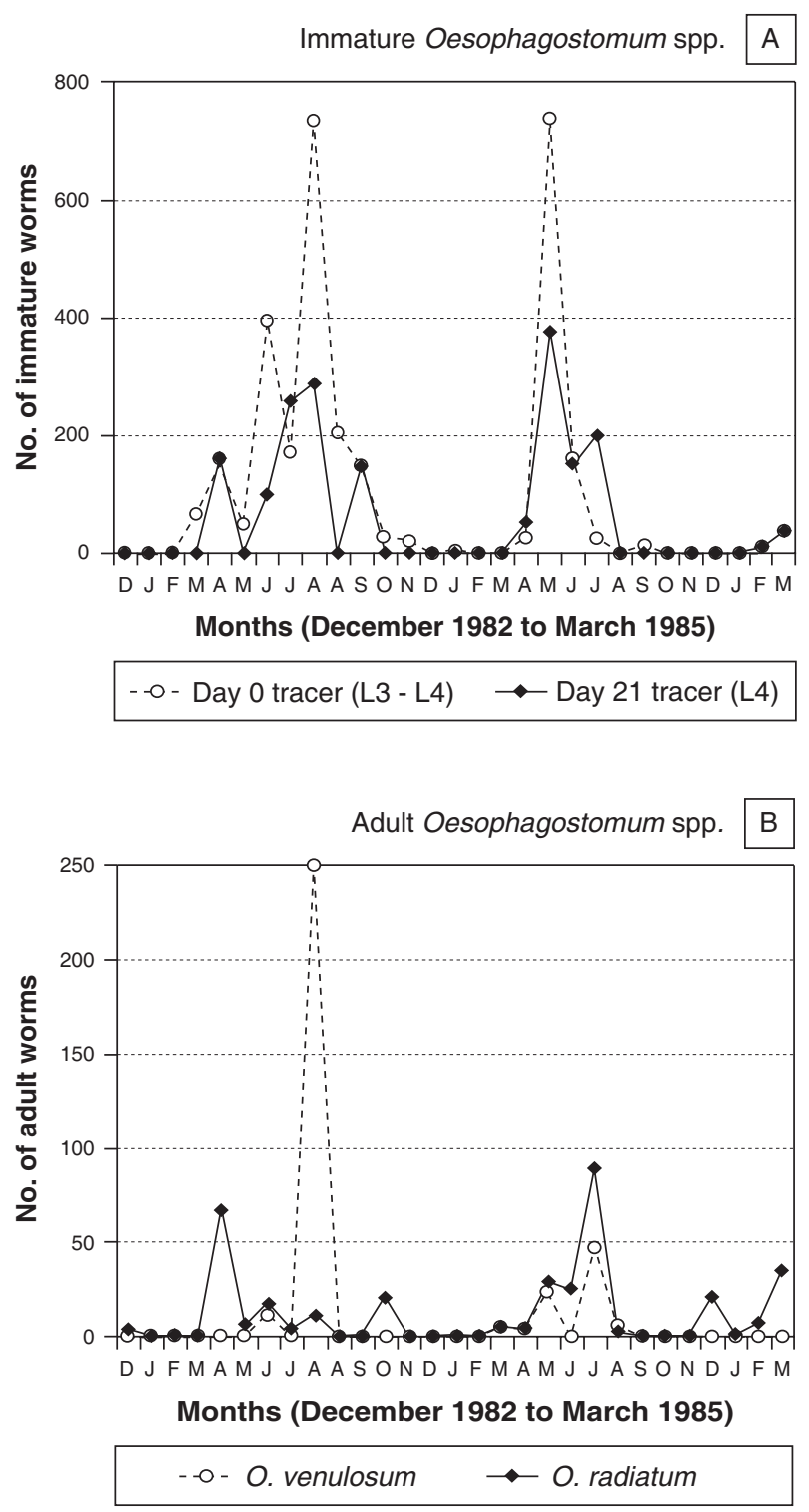

FIG. 7 Seasonality of A) Oesophagostomum spp. larvae, and B) adult Oesophagostomum radiatum and Oesophagostomum venulosum in tracer calves on the farm "Glen Dye", Eastern Cape Province. Two sets of calves were examined during August 1983

infected during summer and autumn. Tracer calves at Nylsvley in Limpopo Province acquired the highest intensity of infection from June to January (Horak 1978), whereas in north-eastern Mpumalanga Province most infection was picked up between November and February (Malan et al. 1982).

The winter prevalence of $O$. venulosum in the calves agrees with that in tracer lambs on coastal pastures in the southern Western Cape Province, where it was most numerous from March to September (Muller 1968). In the south-western region of the latter 
province it was most numerous in sheep on Kikuyu pastures from June to September (Reinecke et al. 1987).

The fourth larval moult of $O$. radiatum takes place 19 days after infection (Andrews \& Maldonado 1941). Consequently a high proportion of fourth stage larvae, even 21 days after removal of the calves from the pastures, cannot be considered as evidence of arrested development. This also explains the absence of adult worms in every day 0 tracer calf. The same probably also applies to $O$. venulosum.

\section{Ostertagia ostertagi}

More $O$. ostertagi were recovered from the tracer calves than all other gastro-intestinal nematodes combined (Table 2), making it the most important helminth species infecting cattle on coastal pastures in the Eastern Cape Province. Horak (1981a) suggested that the geographic distribution of $O$. ostertagi is limited to the Eastern and Western Cape Provinces, and the northern inland surveys of Reinecke (1960b), Horak (1978), Horak \& Louw (1978) Schröder (1979) and Malan et al. (1982), in which no O. ostertagi were encountered, and that of Dreyer et al. (1999) in the eastern Free State, in which a single tracer calf was infested, would seem to support this distribution pattern. However, all 14 calves examined by Louw (1999) on the eastern Highveld of Mpumalanga Province in the north of the country were infected and harboured mean burdens of slightly fewer than 500 worms. Furthermore Tsotetsi \& Mbati (2003) recovered O. ostertagi larvae from the faeces of cattle on the north-eastern Highveld of Free State Province.

The latter findings indicate that a revision of the geographic distribution of this nematode in South Africa is necessary.

Intensity of infection peaked in the tracer calves from July to October 1983 and from June to August 1984 (Fig. 8), but was considerably lower during the latter period than in the former. Infection acquired from the pasture was negligible during the three summers of the survey. Although this pattern of seasonality is similar to that recorded by Williams et al. (1983) in tracer calves exposed on artificial pastures in the temperate Red River Valley region of Louisiana, United States of America, the proportions of arrested larvae differ. In Louisiana these larvae increased from $5.0 \%$ to $79.4 \%$ of the O. ostertagi burdens from late winter to late spring, while on "Glen Dye" they increased from $2.7 \%$ in late winter to $42.3 \%$ in spring. However, at the same time
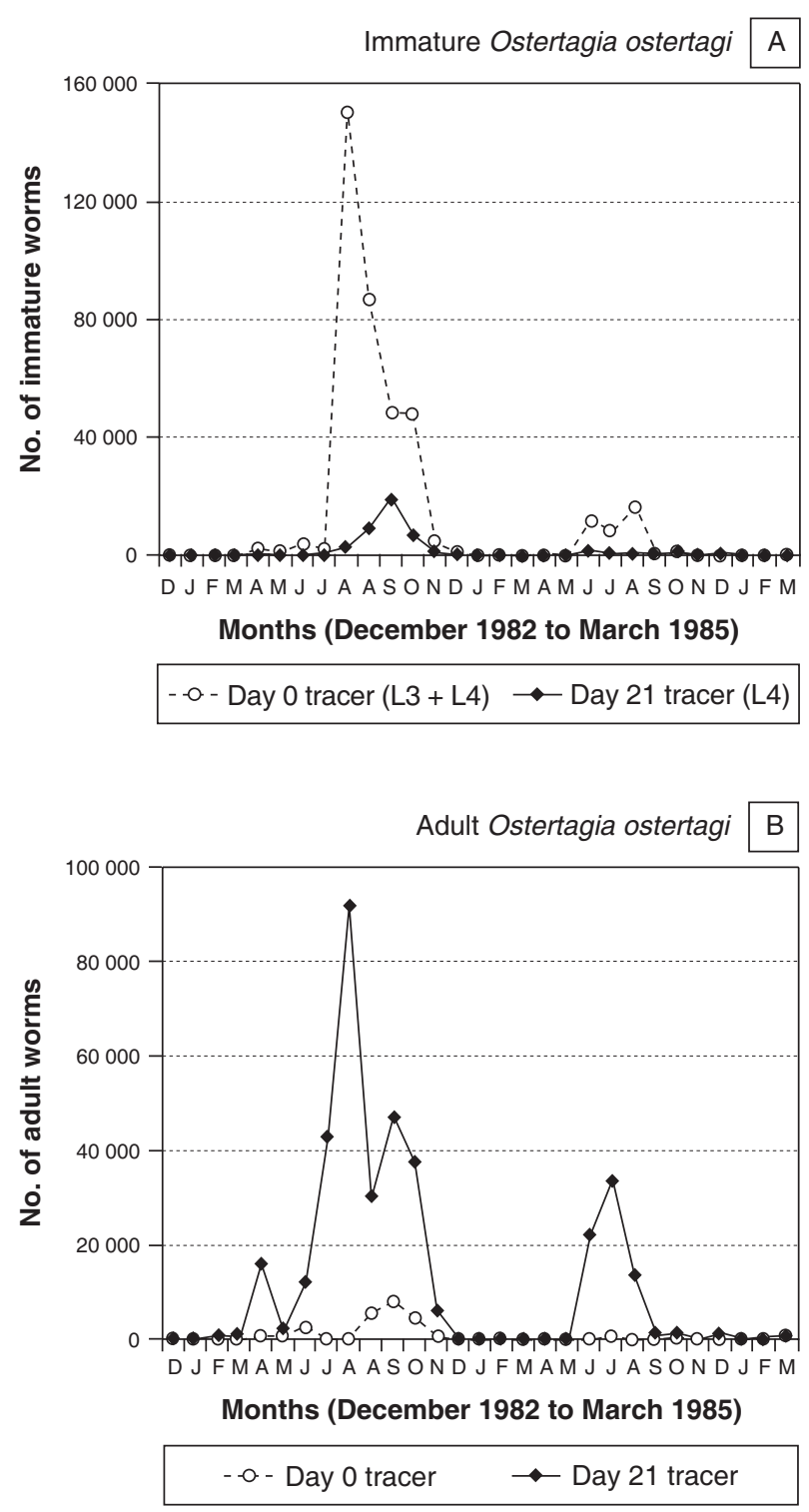

FIG. 8 Seasonality of A) immature and B) adult Ostertagia ostertagi in tracer calves on the farm "Glen Dye", Eastern Cape Province. Two sets of calves were examined during August 1983

as the development of some larvae was arrested, others rapidly developed to adult worms, and 15 days after their first exposure to infection during August and September 1983 the day 0 tracer calves harboured 5625 and 8125 adult $O$. ostertagi respectively.

A total of 2674 third stage larvae were recovered from the various day 21 tracer calves, implying that a small proportion of $O$. ostertagi larvae may be arrested in this stage of development as demonstrated by Eysker (1978) for Trichostrongylus spp. in sheep. 

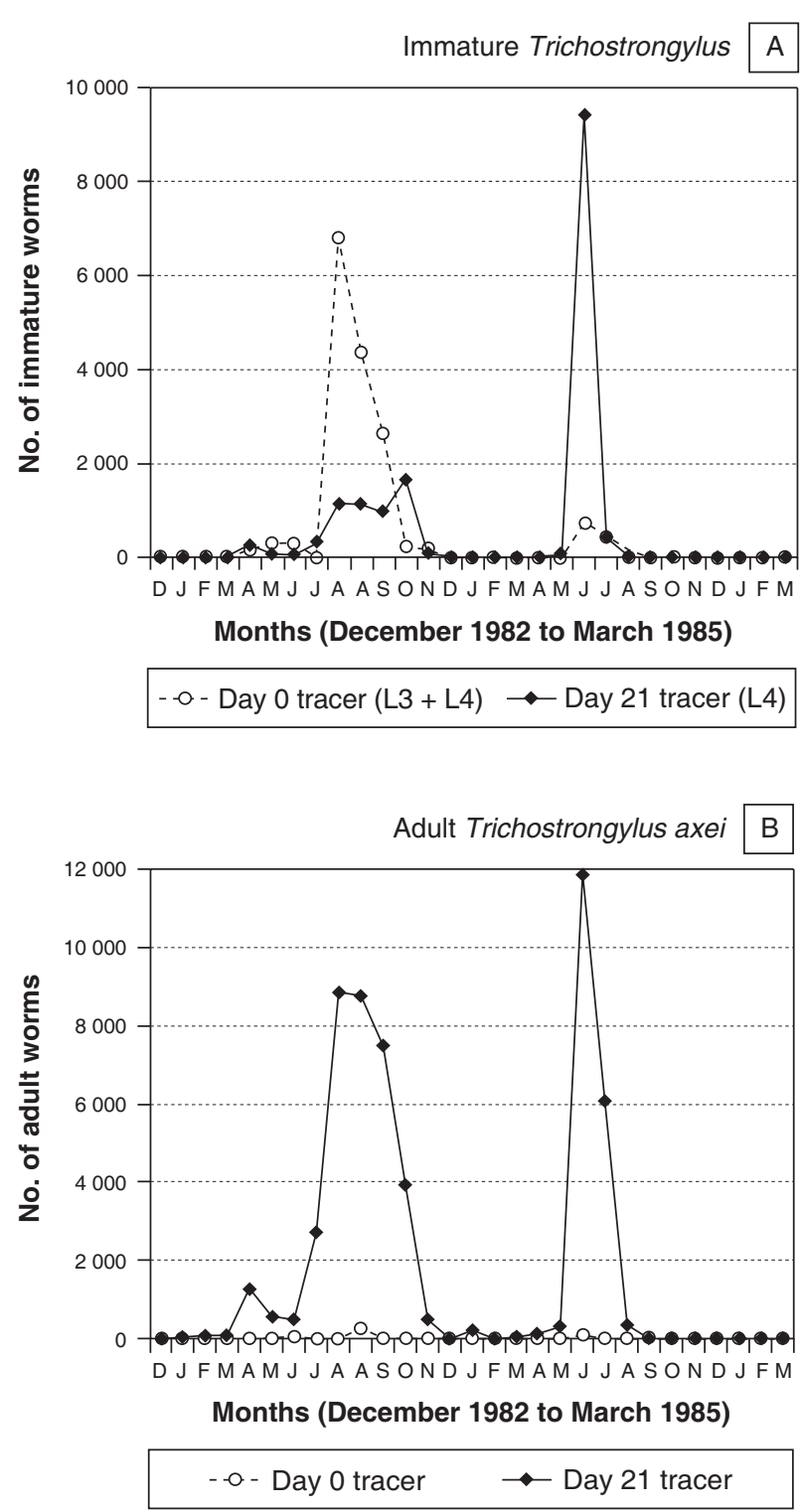

FIG. 9 Seasonality of A) Trichostrongylus spp. larvae, and B) adult Trichostrongylus axei in tracer calves on the farm "Glen Dye", Eastern Cape Province. Two sets of calves were examined during August 1983

\section{Strongyloides sp.}

Third and fourth stage larvae of this genus were identified by the characteristic appearance of their oesophagi. The absence of adult worms reflects either a state of immunity or of host incompatibility.

\section{Trichostrongylus spp.}

With the exception of $T$. axei, worms belonging to this genus are not important parasites of cattle. In surveys conducted on cattle in the eastern Highveld regions of the Free State and Mpumalanga Prov- inces $T$. axei was the most numerous nematode recovered (Dreyer et al. 1999; Louw 1999). In this survey T. axei comprised $99 \%$ of the total number of adult Trichostrongylus spp. (Table 2), and it can safely be assumed that the larvae of this species accounted for a similar proportion of the immature worms. If this assumption is correct only $O$. osterta$g i$ and $C$. oncophora exceeded $T$. axei in numbers in the present survey. The peaks in intensity of infection of adult $T$. axei were similar in both years of the survey, but their duration differed, extending from August to October in 1983 and from June to July in 1984 (Fig. 9). Arrested fourth stage larvae comprised $9.6-28.8 \%$ of the Trichostrongylus spp. burdens in the day 21 tracer calves examined from July to October 1983 , and $44.3 \%$ in the calf examined in June 1984. These calves all harboured more than 20000 adult $O$. ostertagi and four of the five more than 7000 adult $T$. axei, and consequently retardation in the development of the larvae may in part have been density dependent (Smeal et al. 1980b). Third stage larvae were recovered from only one of the day 21 tracer calves.

The fourth larval moult in $T$. axei takes place 10-14 days after infection (Douvres 1957), and yet less than $0.3 \%$ of the worms in the day 0 tracer calves were adult. With the exception of $O$. radiatum, in which the fourth moult takes place 19 days after infection, a considerably greater proportion of the worms of all other species were already adult in the day 0 tracer calves. It would thus seem that irrespective of the magnitude of the worm burden there was some delay in the development of $T$. axei to adulthood.

Trichostrongylus colubriformis, Trichostrongylus rugatus and Trichostrongylus falculatus are parasites of sheep, and the latter two may be common in these animals in the southern regions of the Eastern and Western Cape Provinces (Barrow 1964; Rossiter 1964; Muller 1968; Reinecke et al. 1987; Horak 2003).

\section{Trichuris sp.}

Slightly more than $40 \%$ of the calves were infected with worms of this genus and the presence of adult worms in the day 0 tracer calves indicates that at least some of these worms had been acquired before the calves were exposed on the pastures. It also implies that the double therapeutic dose of albendazole used to clear the calves of infection before exposure had not been effective against this nematode. 


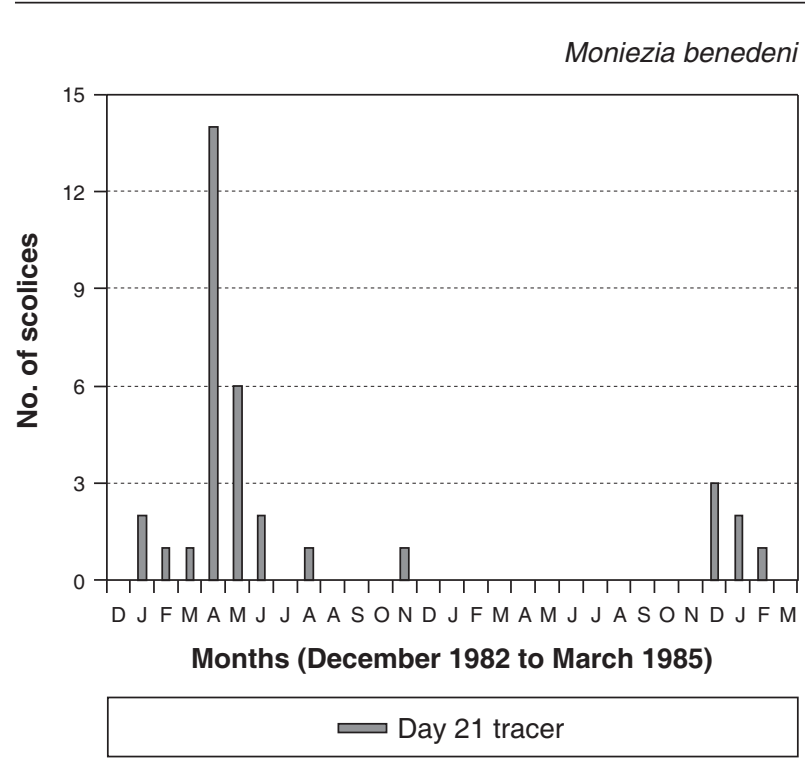

FIG. 10 Seasonality of Moniezia benedeni in tracer calves on the farm "Glen Dye", Eastern Cape Province. Two sets of calves were examined during August 1983

\section{Moniezia benedeni}

This cestode infects cattle and a number of wild bovids, and is especially a parasite of younger animals (Horak et al. 1983; Reinecke 1983). In contrast to the nematodes, $M$. benedeni appeared to favour the summer months and it was present in tracer calves from January to June in the first year of the survey, during November in the second year and from December to February in the third year (Fig. 10). This pattern of seasonality can probably be coupled to the slower development of cysticercoids in their oribatid mite intermediate hosts during the cooler winter months compared to their more rapid development to infectivity during the warmer summer months (Kuznetsov 1970).

\section{General}

The survey commenced during December 1982 on the assumption that, as in previous studies in South Africa, cattle on dry-land pasture, or on natural grazing, acquire most nematode infection during mid and late summer (Hobbs 1961; Horak 1978; Schröder 1979; Malan et al. 1982). This did not materialise and the highest intensities of infection occurred from late autumn to spring, a pattern similar to that recorded for Haemonchus spp. on irrigated pastures on the Gauteng Highveld (Horak \& Louw 1978). However, in the Gauteng survey intensities of infection remained comparatively high during summer, whereas in this study they were generally negligible.
The survival of parasitic nematodes during seasons when external climatic conditions are unfavourable for the development of their free-living stages, is frequently accomplished by arrest in the development of third or fourth stage larvae in the host animal (Michel 1974; Eysker 1978; Horak 1981b). With the exception of $H$. placei, in which arrested development in the fourth larval stage occurred in autumn and winter, early in the season of helminth acquisition, this phenomenon was generally observed in late winter or spring, late in the season of nematode acquisition in this study. It was never a prominent feature despite the fact that the external climate during the summer months seemed to be a limiting factor for the survival or acquisition of the free-living infective stages. Survival of the various nematode species during these months was thus probably achieved via a combination of strategies. Amongst these are a moderate degree of arrested larval development in the host, a residual but ageing population of adult worms, possible survival of larvae in dung-pats on the pasture (Reinecke 1960a), and possible survival of larvae in the soil which then only become available on the herbage during the cooler autumn months (Reinecke \& Louw 1989).

\section{ACKNOWLEDGEMENTS}

We are most grateful to Messrs John and Simon Matthews for making the experimental heifers, experimental grazing plots and other facilities on their farm "Glen Dye" available to us for the duration of the survey. The assistance of Mr J. White with managing the cattle on the farm, Messrs M.M. Knight and E.J. Williams with processing the carcasses for helminth recovery, and of $\operatorname{Dr}$ J.A. van Wyk with reviewing the manuscript is greatly appreciated. This research was wholly financed by a generous grant from Pfizer Central Research.

\section{REFERENCES}

ANDREWS, J.S. \& MALDONADO, J.F. 1941. The life history of Oesohagostomum radiatum, the common nodular worm of cattle. Research Bulletin of the Puerto Rico University Agricultural Experiment Station, No. 2.

BARROW, D.B. 1964. The epizootiology of nematode parasites of sheep in the Border area. Onderstepoort Journal of Veterinary Research, 31:151-162.

BOOMKER, J., HORAK, I.G. \& MACIVOR, K.M. DE F. 1989. Helminth parasites of grysbok, common duikers and Angora and Boer goats in the Valley Bushveld in the Eastern Cape Province. Onderstepoort Journal of Veterinary Research, 56:165-172.

DOUVRES, F.W. 1957. The morphogenesis of the parasitic stages of Trichostrongylus axei and Trichostrongylus colu- 
briformis nematode parasites of cattle. Proceedings of the Helminthological Society of Washington, 24:4-14.

DREYER, KARIN, FOURIE, L.J. \& KOK, D.J. 1999. Gastrointestinal parasites of cattle in the communal grazing system of Botshabelo in the Free State. Onderstepoort Journal of Veterinary Research, 66:145-149.

EYSKER, M. 1978. Inhibition of the development of Trichostrongylus spp. as third stage larvae in sheep. Veterinary Parasitology, 4:29-33.

EYSKER, M. \& VAN MILTENBURG, L. 1988. Epidemiological patterns of gastrointestinal and lung helminth infections in grazing calves in the Netherlands. Veterinary Parasitology, 29:29-39.

FIVAZ, B.H., HORAK, I.G. \& WILLIAMS, E.J. 1990. Helminth and arthropod parasites of Angora goats on irrigated Kikuyu grass pastures in the eastern Cape Province. Journal of the South African Veterinary Association, 61:112-116.

FOURIE, L.J. \& HORAK, I.G. 1990. Parasites of cattle in the south-western Orange Free State. Journal of the South African Veterinary Association, 61:27-28.

HERLICH, H. 1954. The life history of Nematodirus helvetianus, May, 1920, a nematode parasite in cattle. Journal of Parasitology, 40:60-70.

HOBBS, W.B. 1961. Helminth research in South Africa. I. Seasonal incidence of nematode parasites in cattle in the Natal coastal area. Journal of the South African Veterinary Medical Association, 32:151-155.

HORAK, I.G. \& LOUW, J.P. 1978. Parasites of domestic and wild animals in South Africa. VI. Helminths in calves on irrigated pastures on the Transvaal Highveld. Onderstepoort Journal of Veterinary Research, 45:23-28.

HORAK, I.G. 1978. Parasites of domestic and wild animals in South Africa. XI. Helminths in cattle on natural pastures in the northern Transvaal. Onderstepoort Journal of Veterinary Research, 45:229-234.

HORAK, I.G. 1981a. Host specificity and the distribution of the helminth parasites of sheep, cattle, impala and blesbok according to climate. Journal of the South African Veterinary Association, 52:201-206.

HORAK, I.G. 1981b. The similarity between arrested development in parasitic nematodes and diapause in insects. Journal of the South African Veterinary Association, 52:299-303.

HORAK, I.G., DE VOS, V. \& BROWN, MOIRA R. 1983. Parasites of domestic and wild animals in South Africa. XVI. Helminths and arthropod parasites of blue and black wildebeest (Connochaetes taurinus and Connochaetes gnou). Onderstepoort Journal of Veterinary Research, 50:243-255.

HORAK, I.G., KNIGHT, M.M. \& WILLIAMS, E.J. 1991. Parasites of domestic and wild animals in South Africa. XXVIII. Helminth and arthropod parasites of Angora goats and kids in Valley Bushveld. Onderstepoort Journal of Veterinary Research, 58:253-260.

HORAK, I.G. 1999. Parasites of domestic and wild animals in South Africa. XXXVII. Ixodid ticks on cattle on Kikuyu grass pastures and in Valley Bushveld in the Eastern Cape Province. Onderstepoort Journal of Veterinary Research, 66 175-184.

HORAK, I.G. 2003. Parasites of domestic and wild animals in South Africa. XLII. Helminths of sheep on four farms in the Eastern Cape Province. Onderstepoort Journal of Veterinary Research, 70:175-186.

KEITH, R.K. 1967. The life history of Cooperia pectinata Ransom. Australian Journal of Zoology, 15:739-744.

KUZNETSOV, M.I. 1970. Development times of Moniezia cysticercoids in Scheloribates laevigatus under natural condi- tions, in Oribatids and their role in the processes of soil formation, edited by E.M. Bulanova-Zakhvatkina et al. Vilnius: Akademiya Nauk Litovskoi SRR, 223-227. (Abstract Helminthological Abstracts, Series A, 40:3935).

LOUW, J.P. 1999. The helminths of ranch calves in the Northeastern Mountain Grassland of South Africa. Onderstepoort Journal of Veterinary Research, 66:335-338.

MALAN, F.S., REINECKE, R.K. \& ROPER, NANCY A. 1982. The seasonal incidence of helminth parasites of cattle in the eastern Transvaal Lowveld. Journal of the South African Veterinary Association, 53:179-184.

MICHEL, J.F. 1974. Arrested development of nematodes and some related phenomena. Advances in Parasitology, 12: 279-366.

MULLER, G.L. 1968. The epizootiology of helminth infestation of sheep in the south-western Cape. Onderstepoort Journal of Veterinary Research, 35:159-194.

REINECKE, R.K. 1960a. The rôle of infested dung in the transmission of nematode parasites of cattle. Journal of the South African Veterinary Medical Association, 31:45-52.

REINECKE, R.K. 1960b. A field study of some nematode parasites of bovines in a semi-arid area, with special reference to their biology and possible methods of prophylaxis. Onderstepoort Journal of Veterinary Research, 28:365-464.

REINECKE, R.K. 1973. The larval anthelmintic test in ruminants. Pretoria: Department of Agricultural Technical Services. (Technical Communication, no. 106).

REINECKE, R.K. 1983. Veterinary Helminthology. Durban \& Pretoria: Butterworths Publishers (Pty) Ltd.

REINECKE, R.K., KIRKPATRICK, R., SWART, LYDIA, KRIEL, ANNA M.D. \& FRANK, F. 1987. Parasites in sheep grazing on Kikuyu (Pennisetum clandestinum) pastures in the winter-rainfall region. Onderstepoort Journal of Veterinary Research, 54:27-38.

REINECKE, R.K. \& LOUW, J.P. 1989. Overberg research projects. I. The epidemiology of parasitic nematodes in ewes, suckling lambs and weaners. Journal of the South African Veterinary Association, 60:176-185.

ROSSITER, L.W. 1964. The epizootiology of nematode parasites of sheep in the coastal area of the Eastern Province. Onderstepoort Journal of Veterinary Research, 31:143-150.

SCHRÖDER, J. 1979. The seasonal incidence of helminth parasites of cattle in the Northern Transvaal Bushveld. Journal of the South African Veterinary Association, 50:23-27.

SMEAL, M.G., ROBINSON, G.G. \& FRASER, G.C. 1980a. Seasonal availability of nematode larvae on pastures grazed by cattle in New South Wales. Australian Veterinary Journal, 56:74-79.

SMEAL, M.G., FRASER, G.C. \& ROBINSON, G.G. 1980b. Seasonal changes in the structure of nematode populations of cattle in New South Wales in relation to inhibited larval development. Australian Veterinary Journal, 56:80-86.

SUAREZ, V.H., BUSETTI, M.R. \& FORT, M.C. 1992. Epidemiology and effects of nematode infections on beef cow-calf systems of Argentina's western pampas. Veterinary Parasitology, 42: 73-81.

TSOTETSI, A.M. \& MBATI, P.A. 2003. Parasitic helminths of veterinary importance in cattle, sheep and goats on communal farms in the northeastern Free State, South Africa. Journal of the South African Veterinary Association, 74:45-48.

URQUHART, G.M., ARMOUR, J., DUNCAN, J.L., DUNN, A.M. \& JENNINGS, F.W. 1987. Veterinary Parasitology. New York: Churchill Livingstone Inc. 
Parasites of domestic and wild animals in South Africa. XLV

WILLIAMS, J.C., KNOX, J.W., BAUMANN, B.A., SNIDER, T.G., KIMBALL, M.D. \& HOERNER, T.J. 1983. Seasonal changes of gastrointestinal nematode populations in yearling beef cattle in Louisiana with emphasis on prevalence of inhibition in Ostertagia ostertagi. International Journal for Parasitology, 13:133-143. 